\title{
ANALYSIS AND TREATMENT OF PROBLEM BEHAVIOR EVOKED BY MUSIC
}

\author{
Scott D. Buckley and Debra K. NewChoK
}

THE ALLEGRO SCHOOL

\begin{abstract}
The present study investigated the effects of differential negative reinforcement of other behavior (DNRO) on problem behavior evoked by music in a 7-year-old child with pervasive developmental disorder. Following an auditory stimulus assessment, DNRO was used to reduce problem behavior to near-zero levels. Results are discussed in terms of identifying establishing operations to govern treatment options and the use of negative reinforcement when arbitrarily imposed positive reinforcers do not compete with escape from auditory stimulation.

DESCRIPTORS: auditory stimulation, differential negative reinforcement of other behaviour, establishing operations, music
\end{abstract}

Although the nonexperimental literature suggests that a relatively high percentage of individuals with developmental disabilities show some signs of auditory hypersensitivity (Rimland \& Edelson, 1995), only a handful of studies in the behavioral literature have investigated the potential effects of auditory stimulation on problem behavior. O'Reilly, Lacey, and Lancioni (2000) found that background noise was associated with increases in problem behavior in a child with Williams syndrome. Similarly, McCord, Iwata, Galensky, Ellingson, and Thomson (2001) found idiosyncratic influences of auditory stimulation among participants that served as establishing operations (EOs) for problem behavior.

Music is a type of auditory stimulation that has received some attention in the applied literature based on its potential effects as an EO for problem behavior. Recent studies have demonstrated negative influences of music on problem behavior (Iwata et al., 1994; Smith, Iwata, Goh, \& Shore, 1995); however, no study has identified specific variables associated with music that may serve as potential EOs for problem behavior.

Address correspondence to Scott D. Buckley, 14 Willow Terrace, Andover, New Jersey 07821 (e-mail: kegsbuckley@ cs.com). Scott Buckley is now at the Rockaway Township Public School District, Rockaway, New Jersey.

doi: 10.1901/jaba.2006.120-04
Research involving the treatment of problem behavior evoked by auditory stimulation is also scant. McCord et al. (2001) used differential reinforcement of other behavior (DRO) with an arbitrary reinforcer (potato chip) as part of a multicomponent procedure to decrease escape-maintained self-injury during exposure to ascending decibel levels of auditory stimulation. Although this strategy was successful, there may be situations in which arbitrarily selected reinforcers will not compete with the maintaining negative reinforcement contingencies and thus require the use of these contingencies (i.e., escape) to effectively reduce problem behavior.

The present study extends the current research by (a) identifying specific stimuli associated with music that served as an EO for problem behavior and (b) using negative reinforcement to reduce problem behavior evoked by music.

\section{METHOD}

\section{Participant and Setting}

Billy was a 7-year-old boy who had been diagnosed with pervasive developmental disorder and who attended a private school for students with developmental disabilities. He had been referred to the school's behavior support unit by his parents and teachers for exhibiting problem behavior (ear covering and screaming) when exposed to music. Problem 
behavior occurred during car rides, in his classroom, and at home. Observations indicated that although Billy sometimes exhibited the two responses simultaneously, he frequently covered his ears just prior to screaming. Thus, Billy's ear covering was identified as a reliable precursor behavior to screaming. All sessions lasted $5 \mathrm{~min}$ and were conducted two to six times daily in the school's assessment room ( $3 \mathrm{~m}$ by $2.3 \mathrm{~m})$.

\section{Response Measurement and}

\section{Interobserver Agreement}

Disruption consisted of ear covering and screaming. Ear covering was defined as any simultaneous contact of both hands with any part of Billy's ears. Screaming was defined as any high-pitched vocalizations above conversation level. A 10-s partial-interval recording system was used to record all disruption. Interobserver agreement was recorded on an interval-byinterval basis for both responses during $24 \%$ of sessions distributed throughout the study. Agreement was calculated by dividing the number of intervals in which observers agreed on the presence or absence of target behavior (agreements) by the number of agreements plus disagreements and multiplying the result by $100 \%$. Mean agreement on problem behavior was $95 \%$ and ranged from $87 \%$ to $100 \%$. A Radio Shack (III) digital sound level meter was used to measure music volume (in decibels).

\section{Auditory Stimuli Assessment}

An assessment was conducted to determine the influence of variables associated with music that were suspected to evoke problem behavior (e.g., genre and playback source). During each session, Billy had free access to preferred materials (determined via a preference survey and parent and staff reports) and was exposed to a selection from one of four musical genres (pop, classical, jazz, and rock). These selections were played through a portable stereo, either via compact disk (CD) or tape (eight conditions total) in a randomized sequence. Music volume was set at approximately $67 \mathrm{~dB}$, which was consistent with the music volume to which Billy was exposed in most natural settings. In addition, a control condition was conducted in which Billy had free access to preferred materials in the absence of musical stimuli. At the beginning of each music session, the therapist said, "Billy, I have a really cool tape [CD] for you to listen to." The instructor then turned on the music, attended to a magazine, and offered no further verbalizations. Music was terminated for $30 \mathrm{~s}$ contingent on problem behavior.

\section{Baseline}

Because Billy's disruption showed differential sensitivity to taped music irrespective of genre, a selection from one genre of taped music (pop) was used exclusively during all subsequent baseline and treatment sessions. Otherwise, the baseline procedure was identical to that used during the auditory stimuli assessment.

\section{Differential Negative Reinforcement of Other Behavior (DNRO)}

Upon entering the assessment room, the instructor said, "Billy, I'm going to play a really cool tape. If you can sit quietly with your hands down until you hear the beep, I will turn it off." The instructor then set a digital timer to the current DNRO interval and simultaneously started the tape player. Music was terminated for $30 \mathrm{~s}$ contingent on the absence of disruption. Disruption resulted in resetting the timer along with a brief explanation (e.g., "Billy, let's try again with your hands down"). The music remained on during this time. DNRO intervals increased contingent on two consecutive sessions in which disruption occurred during less than $5 \%$ of intervals. The progression of DNRO intervals was $15 \mathrm{~s}, 20 \mathrm{~s}$, $30 \mathrm{~s}, 1 \mathrm{~min}, 2 \mathrm{~min}, 3 \mathrm{~min}$, and $5 \mathrm{~min}$. Sessions 20 and 21 were extended to $7 \mathrm{~min}$ to accommodate the 3-min DNRO interval.

\section{RESULTS AND DISCUSSION}

Figure 1 shows Billy's level of disruption across all conditions during the auditory stimuli 


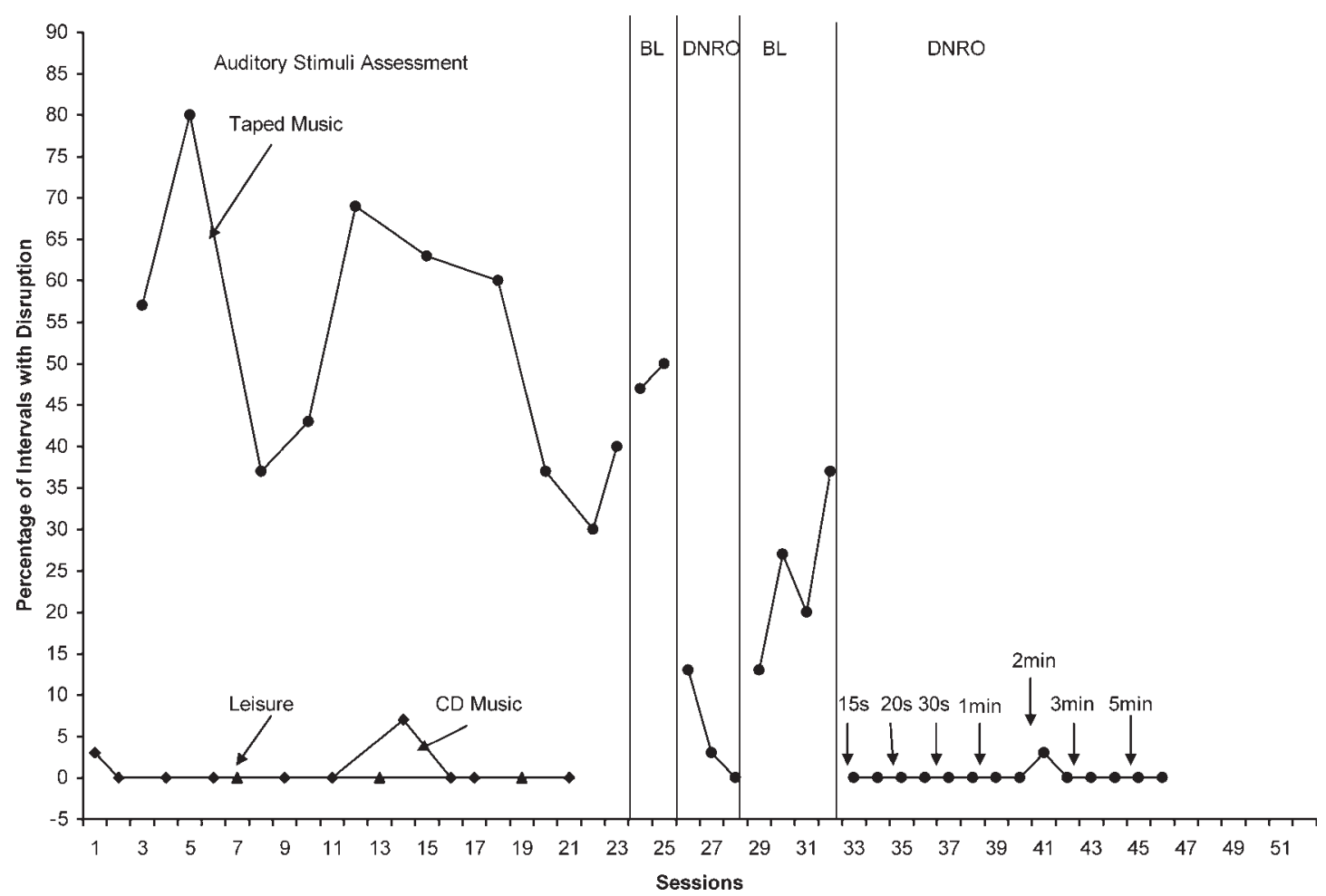

Figure 1. The percentage of 10-s intervals with disruption during the auditory stimuli assessment, baseline, and DNRO conditions.

assessment and DNRO treatment analysis. The results reveal high levels of disruption during the taped music condition relative to CD music and leisure conditions (results did not differentiate as a function of music type). Mean level during taped music was $52 \%$ as opposed to $1 \%$ and $0 \%$ for $\mathrm{CD}$ and leisure conditions, respectively. Billy's mean level of disruption during the postassessment baseline was $48 \%$. This level decreased to $5 \%$ during the first three sessions of DNRO. Disruption increased to $24 \%$ during a return to baseline and declined to near zero when DNRO was reinstated.

The results of the present study extend existing research by showing that EOs for problem behavior evoked by auditory stimulation can be highly idiosyncratic (McCord et al., 2001). More important, it is the first study to effectively treat problem behavior evoked by music based on the identification of a specific EO (e.g., its playback source). This has significance for behavior analysts in terms of emphasizing the benefits of identifying potential EOs prior to designing treatment strategies for problem behavior evoked by music or other forms of auditory stimulation. Likewise, these findings contribute to the growing behavioral literature on auditory stimulation that may help govern the treatment decisions of parents and caregivers.

In addition, this study differs from previous research (McCord et al., 2001) by using negative reinforcement to reduce problem behavior evoked by auditory stimulation. This is particularly important when arbitrarily imposed reinforcers do not compete with existing negative reinforcement contingencies. Future research should directly compare functional (maintaining) reinforcers with those that are arbitrarily imposed to determine their relative effects on problem behavior evoked by auditory stimulation. 
It is unclear why taped playback sources served as an EO for Billy's disruption. Informal observations made by both authors did not reveal differences in sound quality between the $\mathrm{CD}$ and taped music. Possible explanations might involve Billy's familiarity with CDs or his learning history with tapes. Future research is needed to determine the extent to which treatment effects can be generalized to other potential members of an auditory stimulus class and across multiple settings.

\section{REFERENCES}

Iwata, B. A., Pace, G. M., Dorsey, M. F., Zarcone, J. R., Vollmer, T. R., Smith, R. G., et al. (1994). The functions of self-injurious behavior: An experimentalepidemiological analysis. Journal of Applied Behavior Analysis, 27, 215-240.
McCord, B. E., Iwata, B. A., Galensky, T. L., Ellingson, S. A., \& Thomson, R. J. (2001). Functional analysis and treatment of problem behavior evoked by noise. Journal of Applied Behavior Analysis, 34, 447-462.

O’Reilly, M. F., Lacey, C., \& Lancioni, G. E. (2000). Assessment of the influence of background noise on escape-maintained problem behavior and pain behavior in a child with Williams syndrome. Journal of Applied Behavior Analysis, 33, 511-514.

Rimland, B., \& Edelson, S. M. (1995). Brief report: A pilot study of auditory integration training in autism. Journal of Autism and Developmental Disorders, 25, 61-70.

Smith, R. G., Iwata, B. A., Goh, H., \& Shore, B. A. (1995). Analysis of establishing operations for selfinjury maintained by escape. Journal of Applied Behavior Analysis, 28, 515-535.

Received August 16, 2004

Final acceptance October 17, 2005

Action Editor, Richard Smith 